\title{
ethic@ \\ A FILOSOFIA RADICAL DE KARL-OTTO APEL: A COAUTORIA CORRESPONSÁVEL FRENTE ÀS ANOMIAS DA METAÉTICA
}

\author{
KARL-OTTO APEL'S RADICAL PHILOSOPHY: \\ CO-RESPONSIBLE CO-AUTHORSHIP IN THE FACE OF THE \\ ANOMALIES OF METAETHICS
}

\author{
JOVINO PIZZI ${ }^{1}$ \\ (UFPEL/Brasil)
}

\begin{abstract}
RESUMO
A passagem da semântica formal à pragmática promoveu uma transformação na filosofia. O efeito foi consolidar a corresponsabilidade dos sujeitos coautores diante dos problemas de ordem local e mundial. No seu escopo, não há lugar para a metaética. Por isso, Apel pode ser considerado como um filósofo radical. Em termos filosóficos, a corresponsabilidade é sinônimo de coautoria, atitude voltada à convivência hospitaleira. Deste modo, a pragmática apeliana, através dos níveis $A$ e B, exige um compromisso consensual-comunicativo entre humanos, dos humanos para com os não humanos e o ecossistema como tal.
\end{abstract}

Palavras-chave: Pragmática discursiva; Veracidade; Hospitalidade; ConVivência.

\begin{abstract}
The transition from formal to pragmatic semantic promoted a transformation in Philosophy. The effect was to consolidation of co-responsibility of co-authors in face of local and global problems. In its scope, there is no place for metaethics. For this reason, Apel can be considered as a radical philosopher. In philosophical terms, the co-responsibility is synonymous with co-authorship, an attitude aimed at hospitable co-living. In this way, the Apelian pragmatic, through levels A and B, requires a consensual-communicative commitment between humans and humans towards non-humans and the ecosystem as such.
\end{abstract}

Keywords: Discursive Pragmatics; Veracity; Hospitality; Co-living.

\section{Introdução}

Karl-Otto Apel é, sem dúvidas, um dos mais ousados filósofos do século XX, defendendo uma fundamentação pragmático-transcendental da moral. No contexto da pluralidade das teorias e propostas ético-filosóficas, a pragmática apeliana é, entre outras, uma tentativa voltada a responder à complexidade das sociedades de nosso tempo, salientando, por isso 
mesmo, a necessidade de uma transformação da filosofia e de sua responsabilidade social. No horizonte de propostas reconstrutivas e de profunda densidade e delineamentos conceituais, Apel contribuiu decisivamente na configuração de uma corresponsabilidade ético-discursiva de sujeitos coautores.

Sem dúvidas, a pragmática apeliana representou uma renovação singular no campo filosófico contemporâneo, esquivando-se não somente da doutrina "agostiniana dos dois reinos e da apreensão paradoxal, a ela pertencente, do homem como cidadão de dois mundos", mas também do "dualismo kantiano da doutrina quase platônica" (APEL, 1998, 19). Em Apel, a transformação filosófica se processa desde dois períodos diferentes. $O$ primeiro é classificado como sendo gnoseo-antropológico, enquanto o segundo é identificado como pragmático-transcendental. Mais tarde, a reviravolta apeliana recebeu uma complementação, no sentido de uma vinculação entre os dois períodos, aproximação que aconteceu a partir dos a priori do conhecimento (MOLINA-MOLINA, 2019, 1528).

Nesse processo, Apel conseguiu sair da letargia da semântica analítica e da irresponsabilidade de sujeitos observadores, tendência nutrida, inclusive hoje em dia, pelos signatários da metaética. Em vista às exigências de uma orientação ético-política fundamental, "eu não queria cair, de modo algum, em um dogmatismo irreflexivo do compromisso" (APEL, 1981, 17).

Em vista disso, o artigo destaca quatro aspectos. O primeiro se centra na transformação filosófica o que significa, em outras palavras, o rechaço da metaética (1). O segundo item é concernente às considerações de sua filha Dorothea, quem reformula a pretensão de veracidade (2). O terceiro passo trata da corresponsabilidade enquanto exigência de coautoria do sujeito participante (3). Essa noção abre caminho para a hospitalidade, a garantia de uma con-vivência saudável (4).

\section{As anomias da metaética frente à proposta apeliana}

Embora sem conceituar e, muito menos, caracterizá-los topologicamente, Apel alude frequentemente aos a priori do conhecimento, seja em relação aos "interesses cognoscitivos" ou, então, à comunidade de comunicação. No fundo, essa categoria indica a integração entre "a antropologia do conhecimento e a pragmática transcendental da linguagem" (MOLINA-MOLINA, 2019, 1532). O texto não se centra nos diferentes períodos ou no processo que resultou em uma transformação da filosofia transcendental kantiana e dos a priori do conhecimento. 
O foco do texto se atém à transformação filosófica de Apel, cujo insight original foi, segundo Habermas, consolidar a passagem "da semântica formal à pragmática transcendental" (HABERMAS, 2019/2020, 66). Nesse sentido, Apel se destacou, na segunda metade do século XX, porque soube reagir ao "predomínio do positivismo e da metaética" (CORREA CASANOVA, 2019, 16). Nesse sentido, é importante salientar o giro prático ou aplicado da transformação do âmbito moral, sinaliza o início de um movimento significativo no distanciamento "do modelo exclusivamente metaético" e que passa, então, a assumir um giro prático "da filosofia contemporânea" (CORREA CASANOVA, 2019, 17). Deste modo, Apel consegue sintonizar com os problemas relacionados à crescente complexidade das sociedades atuais, propondo uma reconstrução crítica da semântica formal na busca de uma fundamentação pragmáticocomunicativa da responsabilidade com escala planetária (APEL, 2007, 25 ss.).

As considerações a respeito do giro linguístico e a transformação filosófica realizada por Apel identificam a filosofia do final do século $X X$, pois se encaixam no horizonte da fundamentação discursiva da moral. O projeto ético e o acesso à pragmática transcendental foram apresentados em 1994 (PIZZI, 1994, 87 ss.). Naquela época, destacou-se a contextualização das três diferentes tendências da ética contemporânea, indicando não apenas as discrepâncias entre as releituras de MacIntyre e de Apel, mas - e principalmente - ao projeto teórico de Karl-Otto Apel de uma pragmática transcendental (PIZZI, 1994, 86). O modelo de Apel reinterpreta o delineamento kantiano de universalização, e o transforma em princípioponte de forma que todos os sujeitos participantes possam dividir a responsabilidade a respeito das "boas razões" e, assim, elaborar os princípios por meio dos quais os sujeitos podem encontrar um moral of point view comum capaz de "solucionar os problemas" concernentes a todos os afetados (APEL, 2007, 136).

Apenas para realçar, a noção corresponsabilidade é o conceito que mais se aproxima ao de sujeito coautor, uma questão pronominal inerente à consideração dos três pronomes pessoais; e não apenas ao binômio falante versus ouvinte. A intercalação entre falantes vai construindo um processo de interação através da mútua responsabilidade, pois qualquer tomada de decisão exige a interlocução e o assentimento de todos. $\mathrm{Na}$ verdade, não existe a separação entre falantes e ouvintes, pois a noção de "ouvinte" pode dar a entender que o participante seja apenas um assistente e, por isso, um interlocutor passivo, tal como as terceiras pessoas podem ser traduzidas. Não poucas vezes, as terceiras pessoas indicam um sujeito alheio, neutro ou passivo. Por isso, a noção de coautoria indica a interação 
mútua entre todos os participantes - independentemente do pronome pessoal utilizado -, isto é, concernente ao uso de qualquer um dos pronomes pessoais, porque as decisões a serem tomadas e, inclusive, a sua implementação passa a ser um compromisso de todos. No resultado final, não existe tal separação, pois todos os implicados aparecem como coautores corresponsáveis pelas tomadas de decisão.

Tal noção é representativa conquanto ela salienta a dissidência do projeto apeliano da metaética, de modo que essa designação está praticamente ausente nos textos de Apel. O rechaço tem motivo mais que evidente, pois a ética não pode ser uma disciplina autônoma ou, então, transformar-se em um saber filosófico desgarrado do procedimento e das práticas de uma comunidade de comunicação. Por isso, a metaética não faz parte do escopo apeliano. No caso, o giro linguístico já salienta, por si só, um caminho insigne, ou seja, o renomado escopo relacionado ao moral of point view não trata de analisar a linguagem moral, porque a preocupação da ética e da moral é concernente às práticas e os efeitos do agir humano.

Como destaca Adela Cortina, a metaética supõe uma neutralidade em relação ao ponto de vista moral e à própria ética. Por isso, na área dos saberes práticos, isto é, às ações das pessoas e à convivência social, essa neutralidade "é, na prática, impossível" (CORTINA, 2000, 44). Em relação a isso, a neutralidade há, pelo menos, em duas objeções frente às pretensões da metaética. Nesse sentido, há, pelo menos, duas considerações importantes.

Em primeiro lugar (a), a neutralidade supõe que o "ato de julgar" separe e isole o "parecerista" dos fatos e acontecimentos em análise, para auferir o controle um avaliador ad hoc. Por isso, o protagonismo está em alguém completamente alheio e sem qualquer participação no evento ou questão sob judice. Como afirma Apel (1994, 17), nesse caso, o ponto de partida de uma justificação parte de "uma moral privada irracional". Então, o apoio e a referência não concernem ao sujeito participante, mas a uma demonstração ou análise com base na influência intrínseca ao conjunto de postulados lógicos típica do solipsismo metodológico. Com base nas premissas, o procedimento se atém ao exame analítico (crítico) das proposições, para coadunar apenas com o aspecto sintético das predições iniciais. Embora os procedimentos metodológicos analítico e sintético façam parte do escopo, examina-se somente se a premissa pode ser digna de uma apreciação sintética. $O$ aspecto analítico está pré-determinado e, contudo, não é levado em conta, porque o exame da questão obedece ao a priori do próprio método, uma validez pré-determinada pelo procedimento sistemático da verificação das hipóteses em torno a fatos, e nada mais. 
Na linha apeliana, tratar-se-ia de uma "interpretação semânticosintática" típica da "fundamentação lógico-matemática (apodítico-dedutiva" (APEL, 2007, 25). Em termos habermasianos, esse procedimento permanece no horizonte da filosofia da consciência, pois a "problemática da compreensão" se atém a questões cognoscitivas em torno a casos específicos, obedecendo estritamente a dedução lógica da argumentação. Nesse sentido, a neutralidade não admite o giro linguístico, diante do qual a interação entre sujeitos coautores exige a corresponsabilidade, como se destacará a continuação. Evidentemente, a pretensão de uma metaética aufere aos sujeitos apenas a função de julgar, de forma que a análise e a conclusão averiguem a logicidade intrínseca ao raciocínio. Desse modo, há uma obediência à lógica-deductiva para, então, concluir, desde a perspectiva logocentrista, se tal perspectiva pode ser considerada razoável ou não.

Daí decorre a segunda alegação em torno à metaética (b), pois o julgar se reduz à capacidade estrita do observador, um agente "neutro" diante da situação. Evidentemente, esse atributo é pertinente, principalmente em casos alheios ao sujeito que analisa, o qual foi convocado, por exemplo, para o exame de uma determinada situação ou acontecimento. Nesse sentido, um juiz, por exemplo, deveria julgar sem colocar-se a favor, ou contra qualquer uma das partes. Todavia, no ponto de vista moral, não há como isolar sujeitos coautores e, a partir do logocentrismo típico de um raciocínio particular (interior), deliberar a respeito de questões relativas aos sujeitos envolvidos no caso. Assim, a tomada de decisão não depende diretamente dos implicados, mas da decorrência de uma dedução lógica. No caso, as consequências afetam aos coautores, dentre os quais estaria o "suposto" sujeito neutral. Ao tratar-se de ações sociais e intersubjetivas e, ainda, em vistas às consequências, parece difícil - ou impossível - que alguém possa presumir que haja uma neutralidade absoluta e concludente.

Malliandi $(2009,57)$ também menciona problemas da metaética, principalmente frente a critérios distintos dos distintos pontos de vista moral. Sem negar a importância da metaética, Malliandi insiste na "dimensão semiótica" do ethos moral, com seu factum e um dictum. No entanto, o principal problema da semiose, concernente à metaética, relaciona-se à possibilidade de "responder", de forma distinta, ao mesmo factum. Ou seja, os "modelos" de solução dependem, de forma direta, da ou das - premissa constatativa do fato em si. A descrição e a representação do fato relacionam-se a uma série de circunstâncias, cujas técnicas de relato podem omitir ou realçar aspectos que nem sempre são fidedignos. Nesse caso, o descritivismo "equivaleria nutrir a analogia entre proposições 
normativas e descritivas" (MALLIANDI, 2009, 127). E quanto essa relação funcional não consegue a justificação plausível, o emotivismo assume a vanguarda no jugar e passa, então, a impor uma resolução prescritiva de acordo com a lógica interpretativa do sujeito observador.

Diante disso, a metaética apenas - e nada mais que isso - consegue estabelecer uma classificação das diferentes possibilidades de julgar. E para manter a neutralidade e, então, deliberar, o julgador deduz a partir das premissas. No caso de dúvida, ele pode encontrar respaldo na consciência monológica (interior), desconsiderando qualquer expectativa dos coautores. Nesse caso, dever-se-ia considerar a ética como uma questão meramente individual, isto é, na perspectiva das motivações de um sujeito particular, sem qualquer implicação com as relações sociais e com a noção de coautoria.

A matéria relaciona-se à possibilidade de uma reflexão moral a respeito de questões práticas, ou seja, de um estatuto epistemológico capaz de explicar os significados "dos termos morais, da relação lógica entre os julgamentos morais e outras formas de julgamentos" (GRIFFIN, 2003, 170). O problema relaciona-se a uma interposição ou intermediação metafísica, na medida em que presume uma relação entre os julgamentos morais e outras formas de julgamentos, os quais necessitam e se amparam em um terceiro instrumento, isto é, de uma "autoridade" dominante sobre as capacidades morais dos sujeitos. Na verdade, haveria uma prevalência metafísica na composição da estrutura dos julgamentos morais, porque a divergência entre o dictum e o factum necessita sempre de um terceiro interveniente.

Em relação a isso, há duas considerações. A primeira delas relacionase à "autoridade" determinante dos julgamentos, uma metalinguagem que assume a personalidade de mediador e, então, serve de guia ou roteiro para aclarar o significado das expressões e, no final, propor a solução ante os desacordos. Quem ou como justificar essa lógica? Do ponto de vista da filosofia da consciência, a resposta só é possível no espectro de um conhecimento com base na teoria sujeito-objeto. Para Habermas trata-se de um círculo sem saída, pois reflete a autoconsciência de um sujeito monológico. No caso de dúvida ou divergência, a solução exigiria a análise de um alter ego alheio ao caso, cuja capacidade pode afiançar os julgamentos como tal. Trata-se, então, de um procedimento monolíngue e, por isso mesmo, uma lógica argumentativa ligada à filosofia da consciência. Na sua constituição gramatical, quando ego afirma "ser o pai", dever-se-ia então buscar pelos avós ou demais ancestrais e, através disso, aclarar o contorno genealógico para justificar a afirmação. 
Na forma gramatical de uma metalinguagem, o fato de ego afirmar "ser o pai" implicaria na justificação a partir de outras interposições. Desse modo, a locução só seria reconhecida e, portanto, coerente se houver uma explicitação completa da biografia familiar. Nesse sentido, a linguagem moral se limita às circunstancialidades meramente particulares, como é o caso do contorno biográfico de um filho que, na sua certificação familiar, necessitaria do desenho genealógico.

Evidentemente, não há nada que desmereça tal procedimento. A questão chave está no "pressuposto" concernente ao "sentido da argumentação" (APEL, 1994, 37). Por isso, o mais sintomático da metaética relaciona-se à metalinguagem enquanto base metafísica para a justificação dos julgamentos. Em um processo mecanicista, a linguagem informática poderia regrar os julgamentos em conformidade com a escala ou aos contornos de uma programação previamente desenhada. Nessa direção, bastaria definir as estratégias e "encontrar o método óptimo - o algoritmo perfeito - para coordenar os movimentos mentais em relação a qualquer tarefa do conhecimento" (CARR, 2011, 184). Deste modo, os julgamentos obedeceriam a essa lógica algorítmica no sentido de definir as tomadas de decisões. Esse processo se apoia em um sistema de interação metalinguístico sem intersubjetividade comunicativa, pois as decisões estão atreladas ao sistema mecanicista, atrelado a uma programação algorítmica. Assim, a mensuração e a optimização se apresentam como os fundamentos não apenas para as atividades individuais, pois também estabelece critérios para julgar e determinar as decisões para a sociedade. ${ }^{2}$

A segunda inquirição, a respeito de um "sujeito" alheio, parece ser mais interessante, pois a "autoridade" de uma linguagem artificial salienta o enfraquecimento das teorias morais como tal. $\mathrm{Na}$ perspectiva de Habermas, "o programa da ciência unificada" confunde a "unidade da argumentação, isto é, os pressupostos da fundamentação da validez das teorias com a unidade das teorias como tal" (HABERMAS, 1982, 319). Em outras palavras, trata-se da crença em uma única força - a verificação lógico-dedutiva -, que intervém e, ao mesmo tempo, se transforma em ponto de partida e solução final. Deste modo, a fundamentação do ponto de vista moral perde sua capacidade de ser, ao mesmo tempo, uma teoria ética capaz de justificar as tomadas de decisões e, além do mais, salientar suas consequências das tomadas de decisão.

Do ponto de vista moral, se uma teoria não for capaz de justificar as tomadas de decisões e, além disso, não conseguir delinear as consequências de tais decisões, ela não pode ser reconhecida, então, como uma teoria normativa da moral. A questão salienta que há, portanto, uma noção intrínseca a qualquer teoria, de modo que ela pode apresentar-se 
com argumentos plausíveis para, inclusive, julgar as próprias decisões. Em outras palavras, o núcleo de qualquer teoria moral presume uma fundamentação plausível e consistente para julgar e visualizar as consequências relativas ao fato e, por isso mesmo, com a possibilidade de garantir o procedimento participativo para a tomada de decisões.

Sem dúvidas, é plausível a complementaridade entre teorias, assim como existe também uma rivalidade entre as diversas teorias. Por isso, toda ou qualquer teoria normativa da moral não pode depender de pressupostos alheios à sua própria fundamentação, pois a subordinação implica na dependência de uma "autoridade" externa ou alheia. No caso, a pretensão teórica em si perderia o status de teoria. Nesse sentido, os julgamentos das ações ou das consequências dependeriam de um ponto de vista alheio à teoria como tal. Por isso, remeter os julgamentos a outros níveis ou, então, na interposição de outras categorias, implica, entre outras coisas, no arrefecimento dos postulados e categorizações do núcleo consistente da própria teoria normativa.

Nesse sentido, é possível desconfiar dos julgamentos quando a análise moral e as tomadas de decisões são resultado da subordinação a postulados alheios, às vezes delineados de forma artificial. É evidente que diferentes pontos de vista moral - ou seja, teorias normativas da moral apresentam, no seu núcleo consistente, pressupostos distintos. Há também um telos inerente em todas elas. Essa é, sem dúvidas, a riqueza filosófica das diferentes teorias ligadas ao moral point of view. O legado apresenta tentativas importantes, tanto em relação à perspectiva anglofônica e ao modelo neopositivista, assim como são representativas as teorias de Rawls, Cortina, Malliandi, Habermas e Apel, Forst e muitos outros. Nesse interim, o giro pragmático aparece como um dos movimentos mais estudados e comentados dos últimos tempos, embora seja possível tecer críticas tanto aos postulados de Habermas como aos de Apel, da mesma maneira que é possível reavaliar a validez dos pressupostos das demais teorias ou pontos de vista moral.

Nessa direção, a solução apeliana consiste na divisão entre os níveis A e B da ética da responsabilidade. O nível A declina do "círculo lógico (petitio principii)" pois "fundamentar" não significa "deduzir de outra coisa". Para Apel, essa dependência "poderia ser um prejuízo", pois impossibilita (internamente) de a razão "dar razões" (APEL, 2007, 69). Em outras palavras, a dedução simula, desde uma linguagem exógena, a justificação argumentativa das pretensões de validez que afiançam as tomadas de decisão. Daí a parte $B$, através da qual Apel consolida um movimento em direção às implicações normativas, isto é, ao seu compromisso externo. Trata-se, portanto, de uma responsabilidade solidaria, exigindo dos 
coautores a participação e, por isso mesmo, na assunção das consequências (APEL, 2007, 81).

A dupla face da pragmática confere a Apel a índole de "radicalidade". Essa questão é um dos destaques presente no texto de sua filha Dorothea, tema do item a continuação.

\section{Apel sem emotivismo para pensar avec... et contre}

A esta altura, já é possível perceber que a pragmática apeliana abandona qualquer perspectiva emotivista ou de uma casuística falaciosa. A explicação desse distanciamento pode ser encontrada no depoimento da própria filha, Dorothea Apel, em virtude da homenagem organizada pela universidade de Granada, dias 16 e 17 de outubro de 2017.3 Nessa palestra, Dorothea - uma das filhas de Apel e professora da universidade de Witten/Herdecke - salienta "algumas facetas pessoais" de seu pai, embora as dificuldades relacionadas à questão. Para Dorothea, ${ }^{4} \mathrm{o}$ traço fundamental relacionava-se ao fato de "exteriorizar muito pouco seu lado pessoal e adotar, na maioria dos casos, também na vida privada, a atitude argumentativa, crítica e objetiva típica de um cientista" (DOROTHEA, 2018, 27). Por isso, não há motivo para qualquer "sentimentalismo ou exaltação", o que poderia exibir uma imagem "falsa ou tergiversada", porque ele manteve sua personalidade privada consideravelmente reservada.

De certo modo, essa discrição vincula-se ao ambiente e à convivência familiar, sem, no entanto, separar o âmbito pessoal e filial do espaço filosófico. Para a filha, não existia qualquer separação entre "o homem privado do filósofo." $E$ isso pode ser realçado no fato de que "ele viveu de acordo com o que ele interiormente defendia como filósofo" (DOROTHEA, 2018 , 27). Em sua conferência, Dorothea lembra não somente a qualidade de um intelectual comprometido com seu tempo, mas também o leque de interesses de seu pai, como os idiomas e suas conexões etimológicas e sua história, o canto, os esportes, a dança e, inclusive, o naturismo.

Dorothea retoma Habermas, destacando especialmente uma frase de sua fala durante o funeral: "Sempre considerei Karl-Otto Apel como o filósofo autêntico e verdadeiro, como aquele que, além de ter ideias, estava forjado por elas" (DOROTHEA, 2018, 30). Nesse sentido, a discussão argumentativa foi o aspecto mais "autêntico de meu pai" (DOROTHEA, 2018, 31). Pouco apegado a trivialidades ou às "banalidades" da vida, Dorothea insiste na sua peculiaridade filosófica no horizonte de uma veracidade [Wahrhaftigkeit] contagiante.

Todavia, como filósofa e crítica da pragmática transcendental de KarlOtto Apel, Dorothea modifica a noção de veracidade, transformando-a em 
um "pressuposto [Präsupposition] do discurso, com o qual um falante alcança as normas da argumentação e do discurso orientado ao entendimento" (DOROTHEA, 2018, p. 32). Para Dorothea, a veracidade não é uma pretensão de validade exibindo ou expressando as vivências subjetivas do falante, assim como havia sido pensado tanto por Habermas como por Apel. Para Dorothea, a veracidade dispõe de um duplo atributo, até então sem a devida consideração:

Por um lado, a veracidade é o único pressuposto que o falante competente pode granjear (einholbar) com certeza em qualquer momento do discurso. Por outro, esta possível infalibilidade do falante, alegada pelo próprio falante através de sua veracidade, se revela também como necessária. Isso se deve a que a veracidade passa a ser aquele pressuposto através do qual, o falante, alcança pretensões de validade na resolução de todos os pressupostos contrafáticos, ideais e inexcedíveis da argumentação e, ainda, dos discursos e ações (Sprech-/Handeln) voltados ao entendimento (DOROTHEA, 2018, 32).

Na feição inicial, a veracidade evidencia somente aquilo que o sujeito está pensando, sem uma "continuidade lógica", pois as manifestações representam convicções e sentimentos relacionados às vivências particulares, isto é, do mundo interior do falante. De acordo com Habermas, os falantes refletem um conteúdo que não pode ser questionado, pois exprime e, por isso mesmo, dá a conhecer a conexão entre as intenções e o significado das expressões (Cf. PIZZI, 2005, 105-106).

Com a mudança concebida por Dorothea, a pretensão de veracidade significa que todo falante é realmente - e plenamente - "consciente" a respeito daquilo que ele afirma, pois se trata de um aspecto racional da fala. Essa exigência supõe, então, diferentes níveis ou atributos essenciais à veracidade:

O primeiro nível pode ser descrito como o da honestidade proposicional frente a determinados destinatários (um falante deseja realmente que $\mathrm{P}$, tal e como ele afirma). Este nível está vinculado ao segundo, no qual o falante expressa um sentido profundo do querer dizer de modo veraz, cuja disposição do falante está em oferecer razões (begründen) diante da comunidade real do discurso (Um falante pode desejar dizer realmente que $P$, tal e como ele está atestando). Com a intenção de querer afirmar de modo veraz, o terceiro nível 
reza: a assunção da corresponsabilidade do discurso enquanto ação concernente, pois, ao seu impacto e aos efeitos colaterais frente à comunidade real e ideal do discurso, ou seja, não apenas ante os destinatários, mas também aos potencialmente afetados (ao falante, é-lhe permitido afirmar realmente que $P$, tal e como ele o enuncia). Deste modo, 0 resultado refere-se ao fato de que o falante competente "conheça" os três níveis de veracidade e, deste modo, possa alcançá-los tão logo assim o deseje com seriedade (DOROTHEA, 2018, 32-33).

Como é possível perceber, a veracidade não é uma pretensão meramente subjetiva, ou seja, uma manifestação que expressa um sentimento circunstancial ou a revelação de "um aspecto de sua subjetividade" particular - como salienta Habermas -, porque sua validez presume a corresponsabilidade frente às ações. Dorothea admite, pois, uma equidade entre as três pretensões de validade, de forma que os impactos dos enunciados expressivos estejam no mesmo nível da verdade e da retidão (ou justiça). No meu ponto de vista, essa equiparação reforça a ideia de coautoria de todos os concernidos no procedimento discursivo e, em decorrência, nas tomadas de decisão mediadas linguisticamente.

Mas no caso de "o falante" mentir? Ou, então, se ele omitir estrategicamente razões ou justificativas racionais?

Essa possibilidade também é aventada por Dorothea. Como exemplo, ela menciona o exemplo de seu pai, quando se recusou a executar o fuzilamento de "um grupo de prisioneiros russos". Como soldado alemão, ele devia cumprir a ordem. Todavia, "de forma argumentativa e apoiandose no Direito internacional aplicável em casos de guerra", Apel negou-se a cumprir o mandado (DOROTHEA, 2018, 33). Nesse caso, a alegação estratégica ligada ao segundo nível da veracidade se ampara na honestidade justificada no âmbito da corresponsabilidade. Ou seja, no entendimento da filha, seu pai utilizou-se estrategicamente de argumentos para omitir-se e, deste modo, não cumprir a ordem de seu superior, sem, por esse motivo, sofrer qualquer sanção. Esse exemplo evidencia os distintos níveis da veracidade, que revelam uma honestidade radical, isto é, uma "responsabilidade intrínseca à corresponsabilidade" de seus argumentos, tese, afirmações ou exigências como sujeito participante e coautor das alegações e na tomada de decisão.

Essa radicalidade não condiz com o requisito metafísico de uma fundamentação última exógena. A pretensão de veracidade procede de um "pensamento absolutamente veraz e corresponsável que, como inquebrantável disciplina e o rigor inabalável consigo mesmo, se submete 
de modo consequente à exigência filosófica indispensável da validez de sentido" (DOROTHEA, 2018, 34). Trata-se, pois, de uma luta veraz pelo conhecimento, de modo a examinar cada ponto de vista, principalmente as arguições caracterizadas como opostas. O processo de levar em consideração as "posições contrárias" remete a um "Pensar avec... et contre". ${ }^{5} \mathrm{Na}$ verdade, o conhecido refrão, tão consagrado a respeito de Habermas, passa a ser assumido como um aspecto intrínseco ao procedimento, admitindo uma "atitude crítica e dialética" frente às locuções dos coautores. Ou seja, uma atitude filosófica radical de quem, inclusive, nunca evitava "ser confrontado, por meio da crítica, de orientações dissidentes" (DOROTHEA, 2018, 34).

\section{Corresponsabilidade e coautoria participativa}

A transformação da filosofia e a radicalidade filosófica de Apel realça a noção de sujeito como coautor, estabelecendo um novo status aos sujeitos participantes e/ou afetados. Sem dúvidas, trata-se do escopo da pragmática discursiva, mas Apel soube cotejar uma noção de corresponsabilidade que, de acordo com ele mesmo, excede "o conceito da responsabilidade individual imputável ao sujeito singular" (APEL, 2007, 93). Ou seja, esse destinatário monológico é, nos dias de hoje, "insuficiente", pois "na fundamentação e na realização efetiva das execuções de ética aplicada", o escopo tradicional de responsabilidade é deficitário. Diante disso, Apel toma como ponto de partida

a pressuposição heurística de que o conceito de responsabilidade, realmente presumido - ao igual que o conceito de justiça como igualdade de direitos - não pode fundamentar-se estritamente, por nenhuma razão, através de uma Ética racional de estilo tradicional que parta da autarquia do sujeito individual ou, então, da relação sujeito-objeto do conhecimento científico (APEL, 2007, 93).

O desígnio de uma corresponsabilidade - no sentido de uma coautoria compartilhada - rompe com a conjectura de uma suposta neutralidade diante dos fatos e acontecimentos, ao tempo que rejeita a ideia de metalinguagem típica dos correligionários da metaética. Não há, portanto, como separar o fato em si dos sujeitos coautores, de forma que as consequências das decisões sejam objeto de análise exógena. Para Apel, somente a transformação filosófica, com base no giro linguístico, consegue auferir a corresponsabilidade a todos os coautores e, além disso, consolidar 
a própria noção de justiça. Assim, é possível assegurar a imputação dos concernidos, isto é, dos coautores, tanto nos casos particulares como também em situações de "escala planetária". Na verdade, a intersubjetividade trata de ver as consequências do agir - individual e/ou coletivo -, não apenas frente a ciência e à técnica, por exemplo, mas "também em relação ao campo político e econômico" (APEL, 2007, 95).

Nesse sentido, as "responsabilidades do indivíduo" não se limitam às "estratégias da autoafirmação" individual e monológica, porque as consequências das tomadas de decisão não exprimem formas ingênuas ou sentimentalistas de escolhas ou desejos. Além do mais, a globalização é concernente a uma "sociedade do diálogo" (MANCINI, 2019/2020, 97), o que significa, em outras palavras, alimentar laços de convivência saudável. Se, por um lado, a autoafirmação poderia salientar uma neutralidade frente aos desafios planetários, por outro, o reclamo por responsabilização incide no capo da ciência e da técnica, da política, do direito e da economia, entre diversas outras áreas. Ou seja, a corresponsabilidade envolve os sujeitos coautores, sejam eles políticos, empresários, banqueiros ou qualquer sujeito humano, de forma que é possível exigir-lhes o abandono das estratégias sombrias de um "sistema econômico" que "contribui diretamente para o empobrecimento do Terceiro Mundo e, embora indiretamente, à (quase imperceptível) destruição do meio ambiente" (APEL, 2007, 98).

Como é possível perceber, Apel assume a radicalidade filosófica como um projeto de convivência, que é pessoal e coletivo. Na sua autopercepção, ele reafirma o projeto de uma prima philosophia de nível "pós-metafísico e, ao mesmo tempo, transcendental" cuja fundamentação discursiva tem o cuidado de configurar-se como "filosofia prática" (APEL, 1981, 19). Esse escopo pragmático reivindica uma noção de corresponsabilidade com uma dupla face: a parte $A$ e a parte $B$, de modo que a parte $B$ seja "o complemento da parte $A^{\prime \prime}$ frente ao fato de que, lamentavelmente, no mundo atual, "as condições de aplicação da Ética discursiva não estejam, todavia, determinadas" (APEL, 2007, 109).

De acordo com Apel, não há dúvidas que as regras procedimentais de uma Ética discursiva da corresponsabilidade sejam, por certo, bem conhecidas. Na verdade, "ninguém se atreveria a colocar em dúvida a obrigatoriedade" ou, então, "denegar a pretensão" de uma responsabilização eximindo-se do cumprimento de qualquer exigência outorgada pelos coautores. Por isso, a complementaridade entre A e B exige a "aceitabilidade das consequências e subconsequências de nossas atividades coletivas e, ainda, na aprovação de resoluções, contratos e agreements cabalmente relevantes" (APEL, 2007, 109-110). 
A assunção das consequências e dos efeitos do "que é dito" e discutido ainda se ressentem de uma práxis transformadora. Ou seja, a respeito do "muito" do que é dito e discutido, quase nada ou muito pouco é colocado em prática. Nesse sentido, Apel faz alusão a "milhares de colóquios e conferências" e da grande quantidade de

jornadas interdisciplinares de caráter filosófico-científico, passando por debates parlamentares e, inclusive, encontros internacionais sobre problemas como a preservação das condições climatológicas e as reuniões que combinam debates de políticos, economistas e os especialistas em questões como os de ecologia (APEL, 2007, 110).

Sem dúvidas, os recursos destinados a esses conclaves e debates consomem, por assim dizer, grandes vultos. Todavia, os resultados práticos revelam uma considerável face infrutífera. Evidentemente, muitos desses encontros e jornadas não possuem o caráter deliberativo, embora sua índole seja concernente a "discursos práticos". Por isso, os participantes, enquanto sujeitos coautores de uma corresponsabilidade coletiva, deve atribuir-se o caráter de "negociadores" e, portanto, delinear "interações de tipo estratégicas" de modo que suas práticas possam superar os déficits sociais. Nesse sentido, os encontros são sempre uma "alternativa realista" diante da inoperância ou a impotência dos "sujeitos singulares frente às novas responsabilidades pelas consequências futuras de nossas atividades coletivas na ciência, técnica, economia e na política" (APEL, 2007, 110).

Nesse sentido, ganha força o nível $B$, ou seja, as estratégias de aplicação. No caso, os "discursos de aplicação" [Anwendungsdiskurse] referem-se aos aspectos "situacionais que permitam evidenciar a aplicação de uma determinada norma como [angemessen] razoável ou ponderada" (APEL, 2007, 112). Em outras palavras, deve-se, permanentemente, levar em consideração e, ainda, em "orientar-se em vistas a um fim, no horizonte de uma situação histórica, no sentido de cooperar na modificação das relações existentes em vistas a gerar, a longo prazo, as condições de aplicação da Ética discursiva, ou seja, da produção das relações da comunidade ideal de comunicação na comunidade real" (APEL, 2007, 112).

Nesse sentido, a parte $B$ da ética discursiva assume o caráter interpessoal, consolidando a dupla face da responsabilidade moral. O consequencialismo realça o aspecto teleológico. Como já foi salientado, a responsabilidade não é um atributo meramente individual, porque a noção de responsabilidade global e às possíveis consequências futuras do agir social presumem, como imprescindível, a corresponsabilidade de todos, 
tanto na "identificação" como na "solução dos problemas do mundo da vida examinados discursivamente" (APEL, 2009, 149). Deste modo, Apel percebe e configura não apenas uma pragmática com exigências globais, pois ele se preocupa também com os "riscos de uma globalização da terra, ou seja, com as mudanças climáticas que colocam em perigo o futuro do planeta como tal" (BORRELLI, 2019/2020, 6).

Deste modo, é possível chegar a um esboço a respeito da convivência. Ou seja, em tempos de pandemia, parece que o atual modus vivendi se enfrenta a desafios que, de um modo ou de outro, rompem com a noção de normalidade até então vigentes. Em relação a isso, é possível entremostrar duas considerações importantes.

\section{Para consolidar uma hospitalidade convivial}

Diante de uma pandemia com proporções mundiais, a distinção entre crise e colapso permite entender possíveis alcances de suas consequências e, ainda, a possibilidade de revisar a noção de "irreversibilidade" de uma normalidade convencional. O ponto central se relaciona ao Covid-19, um "ator" inesperado que interfere nas tomadas de decisões. Esse "agente" provocou fraturas em diversas esferas da con-vivência, rompendo com os padrões tradicionais da normalidade até então inquestionáveis.

A crise nem sempre significa uma ruína irreversível, enquanto o colapso gera um embaraço e a derrocada de padrões considerados razoáveis. No âmbito conjuntural, a crise aparece quanto há disparidades entre, por exemplo, produção e consumo, com alterações de preços e/ou na moeda, gerando desemprego, desagregação e desorganização de setores da economia. Outra área bastante sensível de crise está relacionada com o sistema financeiro, com riscos substanciais não apenas à economia, mas também a outros setores da sociedade.

O colapso não denota esperança. O vocábulo foi utilizado por roteiristas de cine, autores de livros e pensadores para apresentar o fim de uma situação ou de uma era. Ele se refere à derrocada completa de uma normalidade convencional. Por isso, a noção de colapso revela um grau de intensidade muito mais profundo do que uma situação de crise, ainda que a crise pode levar à insuficiência extrema das energias e provocar uma desintegração irreversível. Então, mesmo conscientes dos perigos, a ânsia em retomar a normalidade pode desqualificar e minimizar as propostas de mudança, pois significariam riscos a um modelo e de um estilo de vida já reconhecidos como normais, mas que demonstraram serem geradores de anomias com alcances sociais e ecológicos sem precedentes. 
Em segundo lugar, o colapso exige repensar muitos aspectos da intersubjetividade. A "nova" normalidade requer, pois, o enfrentamento das patologias com escala global e, na expressão de Apel, "pensar e agir de forma consensual-comunicativa" para que seja possível uma ética da terra. Com certeza, muitos anteveem essa nova perspectiva e, portanto, apostam por mudanças, enfrentando-se àqueles que resistirem e tentam todos os meios para continuar com a mesma normalidade prévia à pandemia. Nesse sentido, a ideia de novas formas de con-viver afiança a "percepção de e $o$ cuidado e a atenção diante de para favorecer o mundo em comum [Mitwelt], estimular a con-vivência [Mitleben] e a compaixão [Mitfühlen]." Em outras palavras, a corresponsabilidade global ressalta o "papel central da educação"6 como alternativa voltada à "consecução da con-vivência" (SCHWAB, 2018, 257). Nesta direção, as interlocuções entre diferentes atores não podem omitir seu compromisso moral e social, principalmente quanto às desigualdades são abismais. Por isso, o fato de calar-se diante das desigualdades sociais e econômicas significa a negação de uma das obrigações essenciais de quem se exime da corresponsabilidade política, econômica e moral na busca de uma convivência saudável entre todos e com a natureza.

$\mathrm{Na}$ verdade, a pandemia revela a eminência de um colapso global, o que implica em redefinir a con-vivência a partir de outros parâmetros. A macro-ética planetária exige, então, enfrentar-se aos perigos e as patologias sociais e, a partir disso, reinventar as formas de con-viver. Os pressupostos de uma "nova" normalidade exigem, portanto, a consideração a todos os sujeitos participantes e, por isso mesmo, concebê-los como coautores nas tomadas de decisão e, inclusive, frente às consequências presentes e futuras. Não se trata de uma questão simplesmente técnica ou de algoritmos, pois a validez de um enunciado ou de qualquer ato de fala se relaciona sempre a um pronome pessoal, participante e participativo. Além de dar a conhecer as justificações das manifestações apresentadas, os coautores podem também exigir de todos os demais justificativas plausíveis. O reconhecimento desse sujeito coautor está ligado a alguém, ou seja, a um coautor com argumentos, não podendo jamais ser desconsiderados ou minimizados.

Por isso, "quem argumenta com seriedade deve [...] empenhar-se para adequar as máximas de seu enfoque pessoal conforme a norma de procedimento do discurso ideal" (APEL 2007, 89). Nessa linha, Apel insiste no princípio regulativo do consenso comunicativo a partir de uma "transformação pós-metafísica da filosofia transcendental de Kant" (APEL, $2007,104)$. A ética não pode ser considerada como um simples fato objetivo, ou seja, como um critério subjetivo, mas em uma capacidade de 
pensar intersubjetivamente os "problemas éticos socialmente relevantes". Em outras palavras, não se trata de um tipo de "dedução monológico a partir de princípios últimos", mas através de "discursos práticos" entre sujeitos iguais e corresponsáveis (APEL, 2007, 108-109).

$\mathrm{Na}$ linha da reformulação da concepção kantiana, é possível também transformar a noção de hospitalidade em exigência para enfrentar o clima de hostilidade, presente em muitas esferas da vida social. O crescente espírito belicoso acomete a convivência e alimenta um clima hostil. Essa ideia está vinculada ao que Kant afirma sobre a hospitalidade, reformulando suas intuições para supor um contexto de mundialização e, ao mesmo tempo, frente aos desafios dos dias atuais. Para caracterizar a hostilidade, Kant utiliza a noção de inospitalidade, ou seja, um "comportamento inospitalário" [das inhospitale Betragen]. Embora seja uma atitude específica da relação entre os Estados, em uma era de mundialização e de pandemia, é possível também averiguar o comportamento hostil nas instituições e empresas, bem como nos âmbitos político, econômico e cultural que, através de atitudes e ações, alimentam e disseminam rivalidades, semeando o medo e o ódio. Esse modo de agir realça um tipo de "insociável sociabilidade" [ungesellige Geselligkeit], eliminando os laços de cooperação, solidariedade e de hospitalidade entre as pessoas e grupos sociais, minando a con-vivência.

Em relação à ideia de hospitalidade de Kant, é possível, então, redimensionar dois aspectos importantes. Em primeiro lugar, a noção já mencionada de uma hospitalidade entre os Estados, mas convertendo o sentido para uma hospitalidade intercultural. Como já foi salientado, se trata também de um espírito hospitaleiro nos ambientes institucionais e empresariais, nos hospitais, igrejas, associações, sindicatos ou em qualquer outra atividade social. Além do mais, esse espírito supõe um exercício permanente que envolve e corresponsabiliza não apenas alguns grupos ou aos representantes governamentais, seja de entidades representativas das nações, mas a própria convivência. Essa corresponsabilidade exige que todos assumam o papel de coautores da transformação social para, então, criar "ambientes" saudáveis. Como é possível perceber, não se trata de uma alternativa à guerra, mas na necessidade de estabelecer princípios para a con-vivência.

O segundo aspecto relacionado à reinterpretação de Kant salienta o direito à hospitalidade, ou seja, de uma con-vivência hospitaleira no planeta "terra". No caso, trata-se de conviver e compartilhar os ambientes dos distintos biomas ou ecossistemas, mas com garantia de uma sustentabilidade ecológica. Em outras palavras, o direito de conviver "na superfície da terra", de forma que o mar e os desertos não sejam tratados 
como áreas hostis (KANT, 1998, 27), mas intimamente ligadas à vida à convivência. Deste modo, a "inospitalidade dos desertos" adquire outro significado e pode, então, transformar-se para fazer parte dos "lugares" vinculados à residência, morada e lugar onde humanos, não humanos e demais seres habitam.

\section{Conclusão}

Através da pragmática, Apel implementa uma reconstrução racional que exige a corresponsabilidade de todos os concernidos, aspecto que consolida o status do sujeito participativo enquanto coautor. Como forma de realçar essa transformação, é possível concluir que há dois delineamentos imprescindíveis. No âmbito interno da moral, a "fundamentação última" [Letztbegründung] diz respeito à "regras de comunicação de uma comunidade ideal e ilimitada de argumentação" (APEL, 2007, 70). Não se trata, portanto, de um simples jogo de palavras, mas na resolução de problemas reais do mundo da vida, de modo que a comunicação busque o entendimento entre todos os participantes. Com o foco no uso e na interpretação do discurso linguístico, as propriedades formais pertencem a "sujeitos reais", de quem se exige o cumprimento das "condições do discurso normativo que eles mesmos" conjecturam na busca da solução interpessoal em torno a questões morais e jurídicas (APEL, 2007, 77).

O segundo bosquejo concerne ao âmbito externo - a parte B -, ou seja, às aplicações, seja em relação às consequências das normas delineadas de forma consensual entre os participantes e, ainda, frente a situações particulares (APEL, 2007, 81). Neste caso, Apel se refere à medicina e a política, na participação em organizações da sociedade civil, partidos políticos, no debate a respeito da crise da "eco- e da biosfera", como também na defesa de um "estado democrático de direito" (APEL, 2007, 83). Nessa direção, Apel menciona também o exercício solidário das funções representativas (cargos públicos e de órgãos de classe ou representativos, por exemplo), na responsabilidade frente aos conflitos e ameaças ecológicas e das guerras e, inclusive, no compromisso pessoal concernente às "máximas do enfoque individual de acordo com a norma de procedimento do discurso ideal" (APEL, 2007, 89). Neste sentido, mais que uma definição, o procedimento requer uma aplicação concreta dos princípios formulados consensualmente. 


\section{Notas}

${ }^{1}$ Professor da Universidade Federal de Pelotas; artigo relacionado ao projeto do Observatório Global de Patologias Sociais, CAPES-PRINT de número 88887.468265/2019-00 (pesquisador visitante na Universidade Jaume I - UJI, fevereiro a julho de 2020).

2 A questão da virtualidade tecnocrática está exposta no artigo "Democracias restrictas al clickbait: La gramática pronominal como respuesta a la virtualidadtecnocrática", em Revista Veritas, Valparaiso, N. 39, abril de 2018.

3 Conferencia realizada na IV Jornada sobre teoria da verdade. Racionalidade crítica comunicativa: homenagem a Karl-Otto Apel, com o título "Karl-Otto Apel mi padre" e publicada em GARCÍA-MARZÁ, D. et all (Coord.). Homenaje a Adela Cortina. Madrid: Tecnos, 2018, p. 27-35.

${ }^{4}$ Por comodidade, as referências concernentes à filha serão apenas por Dorothea (omitindo o sobrenome), enquanto às de Karl-Otto seguirá pelo sobrenome.

${ }^{5}$ Esse foi o título de uma tese de Martine le Corre-Chantecaille (Paris, Étitions de la maison des sicences de l'homme, 2012). Em sua palestra, Dorothea diz que, nesse título, Apel se "sentiu muito bem retratado" (DOROTHEA, 2018, 34).

${ }^{6}$ Além desses aspectos, poder-se-ia frisar a questão da educação e seus percalços. No Brasil, existem, atualmente, evidentes déficits na formação de professores. Como exemplo, há uma tendência em concentrar as licenciaturas em cada curso específico. Ou seja, cada uma das especialidades se encarrega de garantir a licenciatura em graduação. O problema começa quando os professores recémformados chegam aos colégios e devem estabelecer vínculos com colegas de áreas distintas. Então, essa inter-relação, que deveria ocorrer durante o curso de graduação, gera um enorme impacto nos professores, uma experiência nova que deveria acontecer na graduação. Na verdade, o esforço na formação de professores - de reconhecido mérito - deixa de lado a interação para ater-se ao monolinguismo da própria área. Às vezes, as consequências dessa falta de interação se refletem no exercício profissional de quem apenas aprendeu suas habilidades, sem nunca se aproximar de áreas diferentes. 


\section{Referências Bibliográficas}

APEL, Dorothea. Karl-Otto Apel - mi padre. In: GARCÍA-MARZÁ, D. et all (Coord.). Homenaje a Adela Cortina. Madrid: Tecnos, 2018, p. 27-35.

APEL, K.-Otto. Trayectoria filosófica de una sensibilidad hermenéutica. EI programa de la transformación de la filosofía. Una pragmática transcendental del lenguaje: fundamentación última y proyecto reflexivo. Diálogo intersubjetivo y contemporaneidad. In: Revista Anthropos. Barcelona: N. 183, 1981, p. 03-11.

APEL, K.-Otto. Autopercepción intelectual de un proceso histórico. In: Revista Anthropos. Barcelona: N. 183, 1981, p. 12-19.

APEL, K.-Otto. Aspiraciones del comunitarismo anglo-americano desde el punto de vista de la ética discursiva. Comunidad como a priori de la facticidad y como anticipación contrafáctica de la razón. In: FERNÁNDEZ, D. B. et all. Discurso y realidad. En debate con K.-O. Apel. Madrid: Trotta, 1994, p. 15-32.

APEL, K.-Otto. Ética do discurso como ética da responsabilidade. In: Cadernos de tradução. São Paulo: USP, n. 3, 1998.

APEL, K.-Otto. Semiótica transcendental y filosofía primera. Madrid: Editorial Sintesis, 2002.

APEL, K.-Otto. La globalización y una ética de la responsabilidad. Buenos Aires: Prometeo Libros, 2007.

BORRELLI, M. Cambio di paradigma - Dall'ética del discorso di Karl-Otto Apel all'ética della responsabilità plantetaria. In: Topologik, n. 26, v. 2, december 2019 / january 2020, p. 5-8.

CORTINA, A. Ética aplicada y democracia radical. Madrid: Tecnos, 1993.

CORTINA, A. Ética sin moral. 4 ed., Madrid: Tecnos, 2000.

CARR, N. ¿Qué está haciendo internet con nuestras mentes? Superficiales. México: Taurus, 2011.

CORREA CASANOVA, $M$. De la ética a la ética aplicada. In: CORREA CASANOVA, M. et all. Ética aplicada. Perspectivas desde Latinoamérica. Bogotá: Universidad de los Andes, 2019, p. 3-39.

GRIFFIN, J. Metaética. Metaética e ética normativa. In: CANTO-SPERBER (Org.). Dicionário de ética e filosofia moral. V. 2. São Leopoldo: Editora Unisinos, 2003, p.170-174. 
HABERMAS, J. Conocimiento e interés. Madrid: Taurus, 1982.

HABERMAS, J. Von der formalen Semantik zur transzendentalen Pragmatik - Karl Otto Apel ursprüngliche Einsicht. In: Topologik, n. 26, v. 2, december 2019 / january 2020, p. 66-88.

KANT, I. Sobre la paz perpetua. 6 ed., Madrid: Tecnos, 1998.

MALIANDI, R. Ética: conceptos y problemas. 4 ed., Buenos Aires: Biblos, 2009.

MALIANDI, R. Ética convergente. Fenomenología de la Coflictividad. Buenos Aires: La Cuarenta, 2010.

MANCINI, R. Dalla globalizzazione alla società del dialogo. Il seno storicopolitico dell'opero di Karl-Otto Apel. In: Topologik, n. 26, v. 2, december 2019 / january 2020, p. 97-108.

MOLINA-MOLINA, L. Recogiendo el testigo de Karl-Otto Apel. Hacia una integración de la antropología del conocimiento y la pragmática trascendental del lenguaje. In: Revista Pensamiento. V. 75, N. 287, 2019, p. 1527-1554.

PIZZI, J. Ética do discurso. A racionalidade ético-comunicativa. Porto Alegre: EDIPUCRS, 1994.

PIZZI, J. O conteúdo moral do agir comunicativo. São Leopoldo: Editora Unisinos, 2005.

SCHWAB, Hans-Rüdiger. La conectividad del todo. Lou Andreas-Salomé y las implicaciones éticas del concepto Mitleben en el pensamiento moderno. In: GARCÍA-MARZÁ, D. \& Outros. Homenaje a Adela Cortina. Ética y filosofía política. Madrid: Tecnos, 2018, p. 243-257. 